\title{
Implementation of ISO 17025:2005 for the Accreditation of Kafr El-Sheikh Company's Central Laboratory for Drinking water in Egypt
}

\author{
Mohamed H Shaltout ${ }^{1}$ and Waseem A Gad ${ }^{2 *}$ \\ ${ }^{1}$ Reference Laboratory for drinking water, Holding company for water and wastewater, Egypt \\ ${ }^{2}$ Central Laboratory, Kafr El-Sheikh Company for water and wastewater, Egypt
}

*Corresponding author: Waseem A Gad, The Central Laboratory for Drinking water, Kafr El-Sheikh Company for water and wastewater, Egypt.

Received Date: July 29, 2019

Published Date: August 14, 2019

\begin{abstract}
The implementation of quality management system to the central laboratory for drinking water (KFSWCL), Kafr El-Sheikh company for water and wastewater, Egypt was a very important and precise process required the full commitment to the general and technical requirements of the international standards according to ISO 17025:2005 for the accreditation by the national accreditation body (EGAC) and the hard and continued work to achieve all the mandatory elements of the program. As a laboratory's quality management system is thoroughly evaluated on a regular basis to ensure continued commitment and compliance with ISO 17025:2005 accreditation requirements, it has incorporated an overall system for technical and quality management, which results in many benefits observed in the daily laboratory practices. Technical requirements were achieved to include the addition of formal personnel training plans and detailed records, method development and validation procedures, measurement of method uncertainty, and a defined equipment calibration and maintenance program. Other benefits are observed through the high accuracy of workflow inside the laboratory, the Reliability which is derived from performing proficiency tests with accredited international bodies, the trust gained by the customers which is derived from the commitment of the laboratory to operate according to international standards. The implementation of the quality system inside the KFSWCL was a great leap regarding the performance of the laboratory, gained the laboratory the needed commitment and required confidence and raised the performance to an unprecedented limit.
\end{abstract}

Keywords: ISO 17025:2005; Accreditation; Quality management system; Quality assurance; Laboratory; Organization

\section{Introduction}

The central laboratory for drinking water belonging to Kafr El-Sheikh company for water and wastewater is one of the leading laboratories in Egypt in the field of drinking water analysis for its precise procedures and standards that guarantee the quality of the analyses carried out on the water samples taken by the laboratory to ensure the quality of water provided to the consumer. The laboratory has a professional team of chemists responsible for conducting the analyses and applying the necessary quality standards. The laboratory contains the best equipment in the field of physical, chemical and microbiological analyses, which ensures the most accurate results for the analyses carried out according to the Egyptian code for drinking water Hussein et al. [1]. The application and implementation of quality system within the laboratory were to qualify the laboratory for international accreditation according to its General requirements for the competence of testing and calibration laboratories ISO/IEC 17025:2005 PN-EN ISO/IEC 17025:2005 [2].
The application and implementation of quality management system in the central laboratory ensures that the laboratory performs the required tasks with standard methods according to Rice et al. [3] and is useful in increasing the efficiency of the laboratory and raising its validation.

The quality management system includes the following:

1) Ensure that the processes required for the quality management system are created, implemented and maintained.

2) Report to the senior management on the quality management system performance and any requirements required to improve its performance.

3) Ensure enhanced awareness of customer requirements throughout the system.

4) Coordinate with the external evaluation body on all issues related to the external accreditation process. 
5) Establish documented auditing procedures to approve, revise and update all changes to important documents within the QMS.

6) Ensure that records are established and maintained to provide evidence that a quality management system is in place and that there is an existing system for identifying, storing, protecting, retrieving, maintaining and disposing of such records.

7) Ensuring that the quality management system performance is reviewed at specific intervals to ensure that the quality management system continues to be appropriate, efficient and effective; this audit is primarily aimed at evaluating opportunities for improvement and the need for changes to the quality management system.

8) Ensure that quality objectives are identified by senior management to measure QMS performance and that these objectives are reviewed on a regular basis Ratliff [4].

9) Ensure that all new employees are included in the QMS requirements related to their roles and responsibilities and provide necessary qualified training as necessary.
10) Ensure that all suppliers used by the system are selected, evaluated and reassessed, and that the records of this evaluation are maintained.

11) Ensure that senior management conducts periodic and regular evaluations to follow up and ensure customer satisfaction and identify those improvements and their implementation.

12) Work on a programed internal audit system to verify the compatibility of QMS with planned arrangements and that QMS arrangements are effectively implemented and maintained and that corrective actions are taken.

13) Analyze data on the effectiveness of the QMS and assess the possibility of continuous improvement of QMS in the appropriate time and place for such improvements, including data generated as a result of monitoring, measurement and data obtained from other relevant sources and finally.

14) Develop and coordinate ongoing improvements to the quality management system and ensure that corrective and preventive evidence is recorded and reviewed PN-EN ISO/IEC 17025:2005 [2].

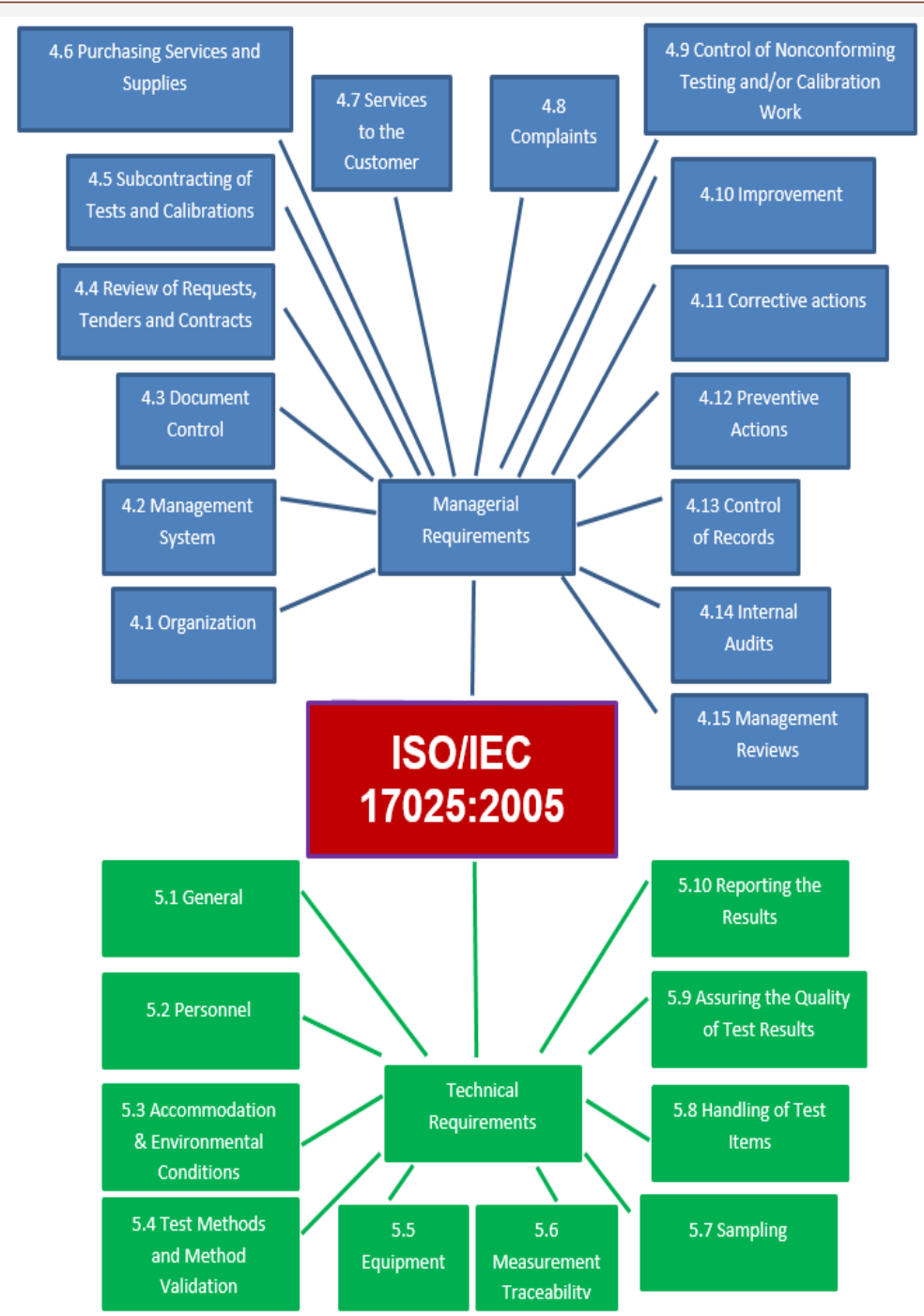

Figure 1: Managerial and technical requirements of ISO 17025 as implemented in the KFSWCL. 
The Central Laboratory team started to work on the implementation of the quality management system in the laboratory in 2017 with the support and qualification of the reference laboratory team, Holding Company for water and wastewater to be accredited in accordance with the followed procedures and with the support of the Chairman of the Board of Directors. The implementation of the quality system in the central laboratory led to the establishment of a sampling section that includes the development and implementation of an annual and weekly plan for sampling and coding samples in a manner that ensures the quality and integrity of the analysis process as well as the validity of all methods used in the measurements to ensure the accuracy of the results as well as the design of a giant database to ensure the preservation of all data and accessibility of any information that may be requested by the laboratory customers.

The system of quality management was built and implemented according to the terms of ISO/IEC 17025/2005 PN-EN ISO/IEC 17025:2005 [2] and Egyptian Accreditation Body (EGAC) has added many advantages to the performance of the central laboratory and is considered a typical development of the laboratory and the whole organization. The Quality management manual describes the Central Laboratory plan for Quality Assurance within the laboratory based on some steps, standards and detailed procedures which deal with all the factors and specifies ensuring that the lab functions

Table 1: The KFSWCL laboratory Scope.

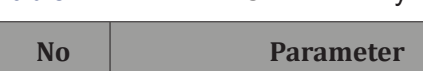

\begin{tabular}{|c|c|c|c|}
\hline No & Parameter & Equipment & Reference Method \\
\hline 1 & Sulphate & Spectrophotometer Sn. 146-190 Model: CECIL Aquarius & EPA 375.2 \\
\hline 2 & Phosphate & $\begin{array}{l}\text { Spectrophotometer Sn. 146-190Sn. 146-190 Model: CECIL } \\
\text { Aquarius }\end{array}$ & EPA 365.3 \\
\hline 3 & $\mathrm{Fe}$ & ICP_OPTIMA 7300 DV & Epa method 200.8 revision 5.4 \\
\hline 4 & $\mathrm{Mn}$ & ICP_OPTIMA 7300 DV & Epa method 200.8 revision 5.4 \\
\hline 5 & $\mathrm{Cu}$ & ICP_OPTIMA 7300 DV & Epa method 200.8 revision 5.4 \\
\hline 6 & $\mathrm{Zn}$ & ICP_OPTIMA $7300 \mathrm{DV}$ & Epa method 200.8 revision 5.4 \\
\hline 7 & $\mathrm{Al}$ & ICP_OPTIMA 7300 DV & Epa method 200.8 revision 5.4 \\
\hline 8 & $\mathrm{Cr}$ & ICP_OPTIMA 7300 DV & Epa method 200.8 revision 5.4 \\
\hline 9 & $\mathrm{Cd}$ & ICP_OPTIMA 7300 DV & Epa method 200.8 revision 5.4 \\
\hline 10 & $\mathrm{~Pb}$ & ICP_OPTIMA 7300 DV & Epa method 200.8 revision 5.4 \\
\hline 12 & Conductivity & Conductivity meter Sn. 07381558 Model: Cond 720 WTW & APHA, 2510 B \\
\hline 13 & $\mathrm{pH}$ & pH Meter Sn. 13321223 Model: 7110unolab & APHA $4500 \mathrm{H}+$ \\
\hline 14 & Alkalinity & - & APHA 2320 \\
\hline 15 & Chloride & - & APHA, 4500 \\
\hline 16 & Hardness & - & APHA 2340 \\
\hline 17 & Fecal Coliform & - & APHA, 9222 D \\
\hline 18 & Total Coliform & - & APHA, 9222 B \\
\hline 19 & Total Algal Count & Microscope Olympus CH-2 & APHA, $10200 \mathrm{~F}$ \\
\hline 20 & $\mathrm{BF}$ & Gas Chromatography Sn. 104551 Model: Varian CP-3800 & EPA, 551.1 \\
\hline 21 & $\mathrm{CF}$ & Gas Chromatography Sn. 104551 Model: Varian CP-3800 & EPA, 551.1 \\
\hline 22 & DBCM & Gas Chromatography Sn. 104551 Model: Varian CP-3800 & EPA, 551.1 \\
\hline 24 & TOC & TOC Analyzer Sn. 07071975 Model: Sievers 5310 C & SMWW $5310 \mathrm{C}$ \\
\hline
\end{tabular}




\section{Managerial and technical personnel}

The laboratory managerial and technical personnel, irrespective of other responsibilities, have the necessary authority and resources needed to meet the mandates assigned to their jobs Ratliff [4].

\section{Customer confidentiality}

It is the policy of KFSWCL to protect the confidential information and proprietary rights of our customers including the electronic storage and transmission of results. The release of test results to anyone other than the customer requires the permission of management. Laboratory reports are reviewed for accuracy prior to release Gad $[7,11]$.

\section{Operational integrity}

The KFSWCL avoids involvement in any activities that would diminish confidence in its competence, impartiality, judgment, or operational integrity. Operational integrity is reviewed by management on a regular basis at management review meetings to ensure continued suitability and effectiveness of laboratory policies and procedures. Any problems are acted on immediately through corrective action procedures Gad [7].

\section{Organizational structure}

The organization and management structure of the laboratory, its place in the parent organization, and the relationships between management, technical operations, support services, and the Quality Management System is defined through organizational charts as showed in (Figure 2).

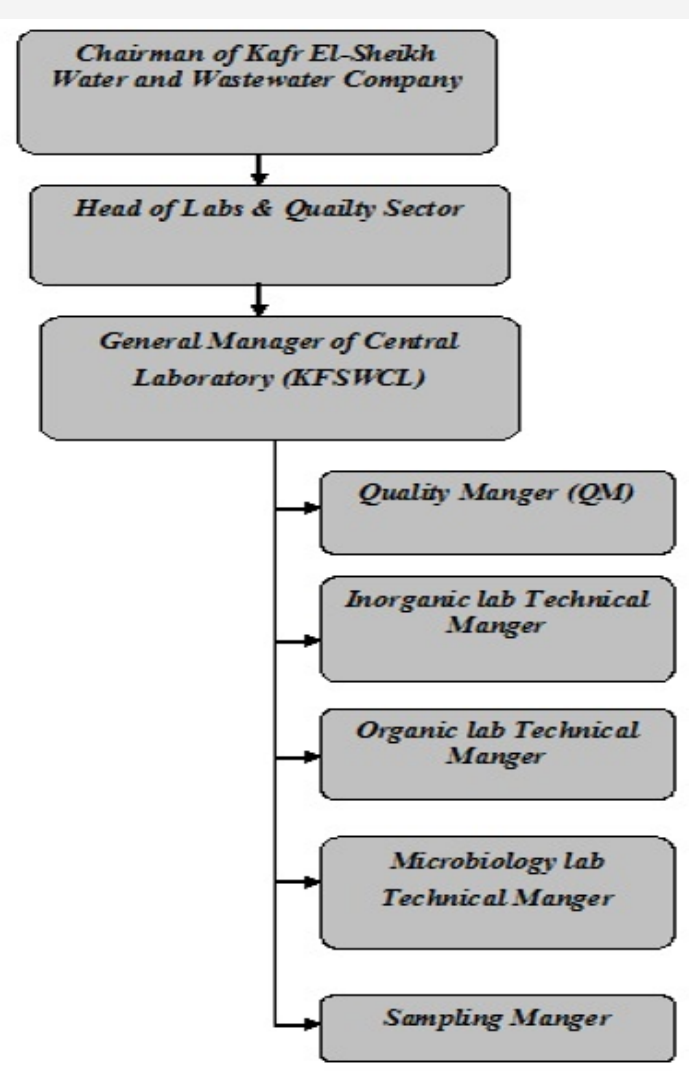

Figure 2: The organization and management structure of the KFSWCL.

\section{Adequate supervision}

The KFSWCL ensures adequate supervision in each area of the laboratory for all testing personnel, including trainees, by providing adequate supervisors who are familiar with the methods and procedures. This is ensured by specific quality procedures and other documents such as this Quality Manual and Work Instructions and another associated documents Gad [7,12].

\section{Communication processes}

The Top Management ensures that appropriate communication processes regarding the effectiveness of the Quality Management System are established within the laboratory. A "Management Group" has been installed encompassing the Quality Assurance Manager, the Technical Managers and the Central Lab General Manager (including the respective deputies); this group meets on a monthly basis Gad [7,13].

\section{Quality management system (QMS)}

The Quality Management System is established, implemented, and maintained by the management. It is applicable to all fields of testing and activities in which the laboratory is involved and undertakes. All policies, systems, programs, procedures and instructions are documented to the extent necessary to enable the laboratory to assure the quality of results generated. These documents are communicated to, understood by, available to, and implemented by the appropriate personnel. The purpose of the Quality Management System is to ensure that all services are in compliance with the requirements of the ISO/IEC 17025:2005 standards PN-EN ISO/IEC 17025:2005 [2].

The effectiveness of the Quality Management System is assessed in several ways as by a program of planned internal audits, covering all aspects of the operation of the quality management system, through regular management reviews assessing the suitability and effectiveness of the quality management system, also by analysis of the potential and actual problems as shown by customer complaints and supplier and subcontractor assessments or based on management group meetings Gad [7].

\section{Commitment to the management system}

The KFSWCL is committed to the development and implementation of the Quality Management System and the continuous improvement of its effectiveness. The effectiveness of the management system is regularly reviewed during the management review Gad [7].

\section{Document Control}

Document Control is necessary to ensure that lab personnel always have access to current policies and procedures. Quality documents that are placed under a controlled distribution include, but are not limited to: The Quality manual, the Standard Operating Procedures, related Procedures and Forms. Control is maintained by initially distributing the documents to the staff members who need to be aware of or need to follow the contained information or procedures Gad [7,2]. 


\section{Review of requests, tenders \& contracts}

The KFSWCL possess its own quality procedures which are used to review requests, tenders, or contracts. Those procedures ensure that the customer requirements including the methods to be used are adequately defined documented and understood, the KFSWCL has the capability and resources to meet the requirements of the customers and The appropriate test methods are selected and capable of meeting the customer's requirements Gad $[7,14]$.

\section{Purchasing services and supplies}

The laboratory quality procedures deal with Purchasing Services and Supplies are used to select and purchase services and supplies for procurement, reception, and storage of supplies. Only services and supplies of the required quality are used. These services and supplies comply with specified requirements. Records of actions taken to check compliance are maintained. These quality requirements are detailed in Inspection of varieties records and will identify the appropriate minimum specifications when necessary Gad $[2,7,14]$.

\section{Service to the customer}

Customer requests are clarified for the customers or their representatives. Furthermore, the customer or their representative will be afforded the right to monitor the performance of the laboratory in relation to the work performed, provided that the laboratory ensures confidentiality to other customers. KFSWCL would inform the customer of any delays or major deviations in the performance of the tests. KFSWCL seeks for feedback from the customer. Positive and negative feedback can be obtained passively through ongoing communications with the customer (e.g., review of test reports with customers) or actively through customer satisfaction surveys. The feedback is used to improve the Quality Management System, testing activities, and customer service Gad $[2,7,14]$.

\section{Complaints}

The KFSWCL has its own quality procedure dealing with Complaints which is used for resolving complaints received from customers or other parties. Records are maintained for all complaints and follow-up. Records of complaints include the following information: details of the complaint, investigation, corrective action and follow-up verification Gad [2,7,15].

\section{Control of nonconforming work}

The KFSWCL quality procedure dealing with controlling nonconforming work is used to control any aspect of testing work, or the results of this work, when they do not conform to the test methods or the agreed requirements of the customer. Where the evaluation indicates that the nonconforming work could recur or that there is doubt about the compliance of the laboratory's operations with its own policies and procedures, the corrective action procedures are followed to identify the root cause(s) of the problem and to eliminate this (these) cause(s) Gad [2,7].

\section{Improvement}

The KFSWCL continually improves the effectiveness of its management system through the use of the quality policy, quality objectives, audit results, analysis of data (Control Charting, PT evaluation, Inter-laboratory testing etc.), corrective actions, Preventive actions and management reviews.

\section{Corrective action}

The laboratory uses quality procedure which is utilized for implementing corrective action when nonconforming work or departures from policies and procedures in the Quality Management System or technical operations have been identified. The procedure requires that appropriate authority must be designated for the implementation of corrective actions. The procedure includes cause analysis, selection and implementation of corrective action, and monitoring of actions. Problems with the Quality Management System or the technical operations of the laboratory might be identified through a variety of activities, such as control of nonconforming work, internal or external audits, management reviews, and feed-back from customers or staff observations Gad [7].

\section{Control of records}

The Control of records quality procedure is used to identify, collect, index, access, file, store, maintain, protect, backup, and dispose quality and technical records. Quality records include reports from internal audits and management reviews as well as corrective and preventive action records Gad [7].

\section{Technical Requirements}

\section{Correctness and reliability}

Correctness and reliability of the performed tests have many contributing factors including: Personnel, Accommodation and environmental conditions, Test methods and method validation, Equipment, Measurement traceability, Sampling, and Handling of test items PN-EN ISO/IEC 17025:2005 [2].

\section{Measurement uncertainty}

The extent to which the factors contribute to the total uncertainty of measurement differs considerably between (types of) tests and between (types of) calibrations. When developing test methods and procedures, KFSWCL takes account of these factors in the training and qualification of personnel, and in the selection and calibration of the equipment it uses Pendrill $[8,18]$.

\section{Personnel}

Competence and qualification: Management ensures the competency of all specific equipment operators, those performing tests, those evaluating results and signing test reports. Appropriate supervision is provided for employees undergoing training. Personnel performing specific tasks are qualified based on appropriate education, training, experience and/or demonstrated skills, as required (Ratliff, 2003). Management defines the minimum levels of qualification and experience necessary for all 
posts within the laboratory. In addition, personnel responsible for the opinions and interpretations included in test reports, in addition to the appropriate qualifications, training, experience and satisfactory knowledge of the testing carried out, also have relevant knowledge of the technology used for the processing of drinking water, or the way it is used or intended to be used and of the defects or degradation that may occur, as well as knowledge of the general requirements expressed in the legislation and standards, also they have an understanding of the significance of deviations found with regard to the normal use of the items, materials, products, etc. concerned Standard [9].

Training Policies and Procedures: Management formulates the goals with respect to the education and the skills of the laboratory personnel. The training program is relevant to the present and anticipated tasks of the laboratory Shaltout [10]. The KFSWCL has quality procedures utilized to identify training needs and providing the necessary training for personnel. The effectiveness of the training actions taken is evaluated. The skills and knowledge are defined in the job description for each job. Management compares the job description to the skills and knowledge of the new incumbent to determine the training needs Gad [7].

\section{Accommodation \& environmental conditions}

Laboratory facilities are appropriate to attain correct performance of tests. This includes but may not be limited to the following: energy sources, lighting, heating, ventilation, dust prevention, humidity control, temperature control, absence of vibration, biological sterility, air quality and any other environmental conditions that may influence the tests. Appropriate care is taken to ensure that the environment does not invalidate the results or adversely affect the required quality of any measurement. This applies especially to the test areas in the laboratory and premises for support such as sample receipt and storage and waste disposal areas PN-EN ISO/IEC 17025:2005 [2].

The technical requirements for accommodation and environmental conditions that can affect the results of tests are documented. Particular care is taken when tests are undertaken at sites other than a permanent laboratory facility (on-site / field tests). Critical environmental conditions are monitored, controlled and recorded as required by the relevant specifications, methods, and procedures or where they may influence the quality of the results. Tests are stopped when the environmental conditions jeopardize the results of the test. Effective separation between neighboring areas is made when the activities are incompatible. Measures are taken to prevent cross-contamination. Segregation of activities is achieved through time and space allocations. Access to and use of areas affecting quality of the tests is defined and controlled and access to the laboratory is restricted to authorized personnel. The authorized personnel are made aware of the following items: The intended use of the area, the restrictions imposed on working within such areas and the reasons for imposing such restrictions. Measures are taken to ensure good housekeeping within the laboratory. Special procedures are prepared when necessary Standard [9].

\section{Test methods \& method validation}

Methods and procedures used for all tests are appropriate as per: Sampling, handling, transport, storage, preparation of items to be tested (sample preparation), estimation of the measurement of uncertainty as well as statistical techniques for analysis of test data where appropriate and Instructions on the use and operation of all relevant equipment and on the handling and preparation of items for testing are available. All instructions, standards, manuals and reference data relevant to the work of the laboratory are maintained current and readily available to personnel. Deviation from test methods must be documented, technically justified, authorized, and accepted by the customer. Methods for sampling and testing are defined in the respective Standard Operating Procedures PNEN ISO/IEC 17025:2005 [2].

The KFSWCL uses tests and/or calibration methods, including methods for sampling, which meet the needs of the customer and which are appropriate for the tests and/or calibrations it undertakes. Preference is given to reference methods published as international, national, or regional standards. If not available, methods published by reputable technical organizations, or defined in relevant scientific texts or journals, or specified by the manufacturer can be used. Laboratory-developed methods or methods adopted by the laboratory may also be used if they are appropriate for the intended use and if they are validated. The KFSWCL ensures that the latest edition of a standard is used unless it is not appropriate or possible to do so. When necessary, the standard is supplemented with additional details to ensure consistent application Gad [7].

The KFSWCL confirms that it can properly operate standardized methods before introducing the tests. The ability of the laboratory to achieve satisfactory performance against documented performance characteristics is verified before samples are analyzed. If the standard method changed, the confirmation is repeated. The customer is informed as to the method chosen; also, the customer is informed when the method proposed by the customer is inappropriate or out of date Standard [9].

\section{Validation of Methods}

Validation of a method establishes, by systematic laboratory studies, that the performance characteristics of the method meet the specifications related to the intended use of the test results ("fit for purpose"). The performance characteristics data are given in each method's Standard Operating Procedures Shaltout $[10,16]$.

\section{Equipment}

The KFSWCL is furnished with all items for sampling, measurement and test equipment required for the correct performance of the tests (including sampling, preparation of test items, processing and analysis of test data). When equipment is used outside the laboratory's permanent control, it ensures that the requirements of the quality management manual are met Gad $[7,17]$. 
Equipment and software used for testing, calibration and sampling can achieve the accuracy required and comply with specifications relevant to the tests concerned. Equipment requiring calibration is labeled to indicate the calibration status and/or operational status and the date when re-calibration is due when appropriate Shaltout [10].

\section{Measurement Traceability}

All measurement and test equipment influencing the accuracy or validity of tests are calibrated and/or verified before being put into service. The extent to which the requirements are followed depends on the relative contribution of calibration uncertainty to the total uncertainty. Test equipment for subsidiary measurements (e.g., for environmental conditions) having a significant effect on the accuracy or validity of the test results or sampling is calibrated before being put into service. The program includes a system for selecting, using, calibrating, checking, controlling, and maintaining measurement standards, reference standards used as measurement standards, measuring and test equipment used to perform tests and calibrations PN-EN ISO/IEC 17025:2005 [2,17].

\section{Sampling}

The KFSWCL conducted quality procedures outline the sampling plan and procedures for sampling. The sampling plan and procedures are available at the location where sampling is performed. Sampling plans are based on appropriate statistical methods whenever reasonable. The sampling plan describes the allocation, withdrawal and preparation of a sample to yield the required information Gad [7,17].

\section{Handling of test items}

The laboratory uses quality procedures describing the transportation, receipt, handling, protection, storage, retention and/or disposal of test items, including all provisions necessary to protect the integrity of the test item by preventing against deterioration, contamination, and loss of identity Gad $[7,14]$.

\section{Reporting the results}

The KFSWCL designed a giant database for collecting and preserving data and reporting the results. The laboratory reports the results of each test or series of tests accurately, clearly, unambiguously and objectively, and in accordance with any specific instructions in the test methods. The results are reported in a test report and include all the information requested by the customer and necessary for the interpretation of the test results and all information required by the method used. Test reports are issued as either hard copy or soft copy Gad $[7,14]$.

\section{Conclusion}

The Implementation of the quality system in the central laboratory as a preparatory step for the accreditation by the national accreditation body (EGAC) was a very precise process that required supreme concern to all details in accordance with the requirements of international standards of ISO 17025:2005. The benefits of this process have been shown in the accurate organization of work within the laboratory and dealing with all factors that may affect the performance of the laboratory and its employees, the continuous and up-to-date training for laboratory staff showed that it was extremely important to maintain the perfect performance through the everlasting development of the manpower inside the laboratory. The new performance of the sampling section under the quality management system made the workflow very regular and the errors were greatly reduced.

The value of the continuous calibration of the laboratory equipment was represented within the extent of importance of maintaining these devices used in the optimum readiness to play its role in the best way. The process of inventorying vendors and suppliers and the periodic and continuous evaluating of their services was a very important step for the procurement process through reliable and trusted foundations with guaranteed previous history of supplying process. The fact that the laboratory periodically performs proficiency tests with external bodies leaded to the continuous confidence in the laboratory results and the ability to rely on its performance by the top management authority. The validation of test methods and the quality control performed by the laboratory made its performance very reliable and the results to be very trustful. It is worth mentioning that the quality management system made dealing with customers very neutral and easy to identify their impression about the performance of the laboratory through customers' feedback and the continuous working to gain their confidence and respond to their complaints. The work within the domain of quality management system had many and many advantages which made the performance of the laboratory and the lab staff develops significantly and leads to remarkable and great success.

\section{Acknowledgement}

It is our honor to be able to acknowledge all of the individuals who guided and assisted us during this project. We would like to thank staff of reference laboratory for drinking water, Holding company for water and wastewater, Cairo, Egypt and staff of the central laboratory for drinking water, Kafr El-Sheikh Company for water and wastewater, Kafr El-Sheikh City, Egypt for their great effort that led to the success of this project. Finally we would like to thank the editorial board and reviewers of Advances in Oceanography \& Marine Biology journal for their consideration and allowing this work to be published..

\section{Conflict of Interest}

No conflict of interest.

\section{References}

1. Hussein RA, Hassan AA, Bakr WM (2009) Assessment of the quality of water from some public coolers in Alexandria, Egypt. J Egypt Public Health Assoc 84(1-2): 197-217.

2. PN-EN ISO/IEC 17025: 2005. (2005) General requirements for the competence of testing and calibration laboratories, Switzerland.

3. Rice A, Baird EW, Eaton RB (2017) APHA 2017 Standard Methods for Examination of Water and Wastewater. Washington: American Public Health Association, American Water Works Association, Water Environment Federation ISBN, USA. 
4. Ratliff TA (2003) The Laboratory Quality Assurance System: A Manual of Quality Procedures and Forms. (3 $3^{\text {rd }}$ edn.), New Jersey, John Wiley \& Sons, USA.

5. Zapata-Garcia D, Llauradó M, \& Rauret G (2007) Experience of implementing ISO 17025 for the accreditation of a university testing laboratory. Accreditation and quality assurance 12(6): 317-322.]

6. Rowley AG (2005) Some Guidance Notes for Method Validation, Statistics and Quality Control for Analytical Chemistry. Alan Rowley Associates.

7. Gad Waseem A (2018) Quality Management manual. (1 $1^{\text {st }}$ edn.), Kafr ElSheikh company for water and wastewater, Egypt.

8. Pendrill L (2008) New developments in measurement uncertainty in chemical analysis. Accreditation and Quality Assurance: Journal for Quality, Comparability and Reliability in Chemical Measurement 13(11): pp: 671-674.

9. Standard B (2006) General requirements for the competence of testing and calibration laboratories. pp: 17025-1999.

10. Shaltout, Mohamed H (2008) Quality Management Manual. (1 $1^{\text {st }}$ edn.), Holding company for water and wastewater, Egypt.

11.(2017) EUROLAB "Cook-Book"-Doc No. 19, Impartiality and Confidentiality. P: 1-2.

12. (2002) EURACHEM / EA Guide 04/10 Accreditation for Microbiological Laboratories, EA/EURACHEM Working Group. P: 1-26.

13. Oliver EL (2018) Implementation of ISO/IEC Practices in Small and Academic Laboratories. The Food Science and Technology Department, University of Nebraska, Lincoln, USA.

14. Ludwig Huber (2009) Understanding and Implementing ISO/IEC 17025, Agilent Technologies, Inc. 2009 Printed in U.S.A., September 3, 2009 5990-4540EN.

15. (2009) Lab Compliance, ISO/IEC 17025 Accreditation Package.

16. B Magnusson, U Örnemark (2014) Eurachem Guide: The Fitness for Purpose of Analytical Methods-A Laboratory Guide to Method Validation and Related Topics, (2nd edn.) ISBN 978-91-87461-59-0.

17. Khodabocus F, Balgobin K (2011) Implementation and practical benefits of ISO/IEC 17025: 2005 in a testing laboratory. University of Mauritius Research Journal 17(1): 27-60.

18. Ellison SL, Rosslein M, Williams A (2000) Quantifying uncertainty in analytical measurement. In: Quantifying uncertainty in analytical measurement. Eurachem. 